\title{
Análise da utilização de dessensibilizante no uso prévio ao clareamento dentário: revisão narrativa
}

\author{
Analysis of the use of desensitizers in the use prior to tooth whitening: narrative review \\ Análisis del uso de desensibilizantes en el uso previo al blanqueamiento dental: revisión \\ narrativa
}

Flávio Augusto de Moraes Palma ${ }^{1 *}$, Gustavo Baruc Andrade Abreu ${ }^{1}$, Tamires Mirely Reis Silva ${ }^{1}$, Victor Arthur Rodrigues de Souza1', Ezequiel Santos Barbosa1, Gabriel Santana Freire', Gabriel Santos Neves ${ }^{1}$, Mariana Matos de Souza², Letícia Martim³ ${ }^{3}$ Flavia Pardo Salata Nahsan.

\section{RESUMO}

Objetivo: Analisar se existe eficácia na utilização de dessensibilizantes antes do tratamento clareador para a diminuição da sensibilidade dentária. Revisão bibliográfica: Para os pacientes que possuem dentes vitais escurecidos, 0 clareamento dentário é um dos procedimentos odontológicos mais solicitados pelos pacientes que querem um sorriso mais agradável. Diante do tratamento de clareamento dentário, é de extrema importância ter o conhecimento que devido a penetração do agente clareador nos túbulos dentinários, devido à perda de mineral dental, é onde pode ocorrer a sensibilidade dentinária. A sensibilidade dentinária ocorre devido à desobliteração dos túbulos dentinários, onde ocorre a comunicação do meio externo com o tecido dentinário. Uma das alternativas para controlar ou diminuir a sensibilidade dentária após ou durante um tratamento clareador é a utilização de dessensibilizantes, onde sua principal função dos agentes dessensibilizantes e obliterar os túbulos dentinários. Considerações finais: A técnica com comprovação de eficácia indicada por estudos clínicos controlados indica o uso de géis dessensibilizantes previamente ao clareamento em consultório.

Palavras-chave: Clareamento dental, Sensibilidade dentária, Dessensibilizantes dentinários.

\begin{abstract}
Objective: To analyze whether there is effectiveness in the use of desensitizers before the bleaching treatment for the reduction of tooth sensitivity. Bibliographic review: For patients who have darkened vital teeth, tooth whitening is one of the most requested dental procedures by patients who want a more pleasant smile. In the face of tooth whitening treatment, it is extremely important to have the knowledge that due to the penetration of the whitening agent in the dentinal tubules, due to loss of dental mineral, this is where dentinal sensitivity can occur. Dentin tenderness occurs due to the deblocking of the dentinal tubules, where the external environment communicates with the dentinal tissue. One of the alternatives to control or decrease tooth sensitivity after or during a whitening treatment is the use of desensitizers, where their main function is desensitizing agents and to obliterate the dentinal tubules. Final considerations: The technique with proven efficacy indicated by controlled clinical studies indicates the use of desensitizing gels prior to whitening in the office.
\end{abstract}

Keywords: Tooth bleaching, Dentin sensitivity, Dentin desensitizing agents.

\section{RESUMEN}

Objetivo: Analizar si existe efectividad en el uso de desensibilizantes antes del tratamiento blanqueador para la reducción de la sensibilidad dental. Revisión bibliográfica: Para los pacientes que tienen dientes vitales oscurecidos, el blanqueamiento dental es uno de los procedimientos dentales más solicitados por los pacientes que desean una sonrisa más agradable. De cara al tratamiento de blanqueamiento dental, es de suma importancia tener el conocimiento de que debido a la penetración del agente blanqueador en los túbulos dentinarios, debido a la pérdida de mineral dental, es aquí donde puede ocurrir la sensibilidad dentinaria. La sensibilidad dentinaria se produce debido al desbloqueo de los túbulos dentinarios, donde el entorno externo se comunica con el tejido dentinario. Una de las alternativas para controlar 0 disminuir la sensibilidad dental después o durante un tratamiento blanqueador es el uso de desensibilizantes, cuya función principal es la de agentes desensibilizantes y obliterar los túbulos dentinarios. Consideraciones finales: La técnica con eficacia probada indicada por estudios clínicos controlados indica el uso de geles desensibilizantes antes del blanqueamiento en el consultorio.

Palabra clave: Blanqueamiento de dientes, Sensibilidad de la dentina, Desensibilizantes dentinarios.

\footnotetext{
${ }^{1}$ Universidade Federal de Sergipe (UFS), Lagarto - SE. *E-mail: flavioampodonto@gmail.com

2 Universidade Veiga de Almeida (UVA), Rio de Janeiro - RJ.

${ }^{3}$ Clínica Oral Santa Helena (OSH), Itabaiana - SE.

${ }^{4}$ Universidade Federal de Sergipe (UFS), Aracaju - SE.
} 


\section{INTRODUÇÃO}

O clareamento dental é um procedimento estético em crescente aumento na Odontologia, onde cada vez mais os pacientes estão preocupados com a aparência e principalmente com o sorriso. Para os pacientes que possuem dentes vitais escurecidos, o clareamento dentário é um dos procedimentos odontológicos mais solicitados pelos pacientes que querem um sorriso mais agradável, uma vez que as alterações dentárias que comprometam a harmonia bucal do paciente, podem trazer sérias consequências sobre sua imagem social, e clareamento dental por se tratar de uma eficiente opção conservadora, porquanto parte para procedimento de facetas, coroas e tratamentos microabrasivos, acaba se tornando mais invasivos que o clareamento dentário, sendo assim o clareamento dentário torna-se um procedimento satisfatório para o paciente (CRESCENTE CL e PINTO CF, 2016; FERREIRA DO, et al., 2014; OLIVEIRA JAG, et al., 2014).

Diante do tratamento de clareamento dentário, é de extrema importância ter o conhecimento que devido a penetração do agente clareador nos túbulos dentinários, devido à perda de mineral dental, é onde pode ocorrer a sensibilidade dentinária. O clareamento dental pode ser realizado através de diferentes técnicas: clareamento caseiro, clareamento em consultório e a técnica associada de clareamento. Os agentes clareadores funcionam de uma maneira bem simples, onde ocorre a decomposição do peróxido em radicais livres, onde os mesmos irão quebrar as moléculas amplamente pigmentadas em pequenas moléculas com menor número de pigmentos, através da oxidação e redução das mesmas (SILVA FMM, et al., 2012; REZENDE M, et al., 2014).

Diante dos tratamentos de clareamento dental, a sensibilidade dentária continua sendo o efeito colateral mais relatado entre os pacientes. Em grande maioria dos tratamentos de clareamento dental, é bem comum que os pacientes submetidos a tal procedimento em dentes vitais relatem sensibilidade ou desconforto durante o tratamento, por conta da perda de mineral e pelo efeito nocivo peróxido de hidrogênio nos tecidos pulpares. A sensibilidade parece ocorrer pela penetração de agente clareador nos canalículos dentinários (FERREIRA DO, et al., 2014; CERQUEIRA RR, et al., 2013). Agentes dessensibilizantes que possuem na composição fluoretos e nitrato de potássio em têm apresentado bons resultados à redução da sensibilidade pós-operatória ao térmico do tratamento de clareamento dental (CRESCENTE CL e PINTO CF, 2016).

A utilização de agentes dessensibilizantes à base de fluoretos e nitrato de potássio utilizado anteriormente ao clareamento caseiro e de consultório, alega obter resultados satisfatórios na redução da sensibilidade dentária. Conforme o procedimento clínico é realizado, para minimizar o tempo de trabalho dos cirurgiões dentistas, foram criados em forma de géis clareadores os dessensibilizantes com as substancias de gluconato de cálcio, na tentativa de conter a sensibilidade dentinária e principalmente reduzir o temo de trabalhos dos cirurgiões dentistas. Substancias como os fluretos podem bloquear as respostas nervosas devido ao seu efeito de obliteração dos túbulos dentinários, e as substancias de nitrato de potássio ajudam a reduzir a irritabilidade das fibras nervosas na câmara pulpar, impedindo assim, a comunicação de sinais dolorosos ao sistema nervosos central (CERQUEIRA RR, et al., 2013; CRESCENTE CL e PINTO CF, 2016).

Criar maneiras que permitam diminuir ou neutralizar a sensibilidade, aumentam a satisfação do paciente e a adesão e colaboração ao tratamento do clareamento dental. Partindo do pressuposto que o tratamento de clareamento dental pode causar a sensibilidade dentária, o uso de dessensibilizantes pode ser utilizado antes ou após a aplicação dos agentes clareadores (CRESCENTE CL e PINTO CF, 2016).

O uso de um gel dessensibilizante ( $5 \%$ de nitrato de potássio / $2 \%$ de fluoreto de sódio) antes do clareamento em consultório não afeta a eficácia de branqueamento, mas é capaz de reduzir a sensibilidade dos dentes. Em relação ao pós clareamento dental, os dessensibilizantes utilizados após o clareamento ou em mistura no gel clareador foram capazes de aumentar a microdureza do esmalte, ou seja diminuir a sensibilidade dentária (KUTUK ZB, et al., 2019).

Com um amplo mercado de produtos dessensibilizantes e agentes clareadores, muitos cirurgiões dentistas acabam ficando em dúvida em qual material utilizar e qual procedimento realizar, assim como se faz necessário o uso de dessensibilizantes, antes ou após o tratamento clareador. Diante das necessidades envolvidas, este estudo tem como objetivo principal, analisar se existe eficácia na utilização de dessensibilizantes antes do tratamento clareador para a diminuição da sensibilidade dentária. 


\section{REVISÃO BIBLIOGRÁFICA}

\section{Tipos de clareamento e agentes clareadores}

Diante da demanda dos pacientes em busca da estética perfeita, as indústrias estão desenvolvendo novos produtos e assim como os cirurgiões dentistas desenvolvem novas técnicas sendo elas menos invasivas aos tecidos dentais para fornecer um tratamento eficaz e satisfatório aos seus pacientes. Sendo assim o clareamento dentário vem se tornando uma eficiente opção para os cirurgiões dentistas, sendo ela uma técnica conservadora quando comparado a procedimentos mais invasivos como a microabrasão, facetas e coroas. Hoje, o tratamento clareador para dentes vitais pode ser realizado através de duas técnicas: a caseira ou de consultório (CRESCENTE CL e PINTO CF, 2016; SILVA FMM, et al., 2012)

A técnica caseira, como o próprio nome já diz, é realizada na casa do paciente, por ele mesmo, porem supervisionada pelo cirurgião dentista, a qual irá indicar qual agente clareador será ideal para o paciente, assim como moldar a moldeira personalizada. Os agentes mais utilizados ultimamente são os peróxidos, sendo que uso de peróxido é agora geralmente aceito como um tratamento seguro e eficaz para dentes que necessitam de clareamento, podendo ser eles os agentes clareadores peróxido de carbamida ou peróxido de hidrogênio, em concentrações variadas. Independente do agente clareador, o mecanismo de ação dos agentes clareadores é o mesmo, pois eles funcionam como veículos de radicais de oxigênio (SILVA FMM, et al., 2012).

A técnica caseira como já relatado anteriormente, necessita uma supervisão do cirurgião dentista, e tem como pontos de vantagens o agente clareador ser pouco agressivo aos tecidos, tem um menor custo, possui uma menor recidiva de cor à longo prazo e as sessões das consultas são rápidas e poucas. Assim por outro lado, tem como desvantagens a necessidade da colaboração do paciente, pois é o mesmo que irá inserir o agente clareador na moldeira, e necessita de uso diário pelo tempo ao qual o cirurgião dentista recomendou, e também tem como desvantagem a falta de adaptação por parte dos pacientes em relação ao uso das moldeiras (SILVA FMM, et al., 2012).

O clareamento em consultório foi validado como eficaz para clarear a cor dos dentes, utilizando agentes clareados como peróxidos em altas concentrações, variando de $20 \%$ a 38\% (PONTAROLLO GD e COPPLA FM, 2019; KUTUK ZB, et al., 2019). No tratamento realizado em consultório, é comum o uso de concentrações de peróxido de hidrogênio que variam de $25 \%$ a $50 \%$ e peróxido de carbamida de $35 \%$, com ou sem fontes de luz, controlado pelo dentista. Pode se dizer que diferentemente da técnica caseira, onde o procedimento depende do paciente, no de consultório depende exclusivamente do cirurgião dentista, obtendo maior controle de aplicação, sendo um ponto vantajoso, por outro lado, como o tratamento no consultório necessita de mais de uma sessão, isso acaba aumentando o custo do tratamento, sendo um ponto negativo para o mesmo, além disso, há maior índice de recidiva de cor a curto prazo (BARBOZA DC, et al., 2017).

Diante dos agentes clareadores e suas indicações (Quadro 1), todos obtêm um resultado satisfatório para o paciente.

Quadro 1 - Agentes clareadores e suas indicações.

\begin{tabular}{|c|c|c|}
\hline Agentes clareadores & Tratamento Caseiro & Tratamento de consultório \\
\hline Peróxido de Carbamida & $10 \%$ a $22 \%$ & $35 \%$ a $38 \%$ \\
\hline Peróxido de Hidrogênio & $1,5 \%$ a $10 \%$ & $25 \%$ a $35 \%$ \\
\hline
\end{tabular}

Fonte: Palma FAM, et al., 2021; adaptado de Cardoso PEC, et al., 2014.

\section{Sensibilidade pós clareamento dental}

A sensibilidade dental é um efeito comum após o clareamento e pode ser dependente do tempo de tratamento, concentração do peróxido e tipo de agente clareador. A sensibilidade dental que ocorre no clareamento normalmente não é severa e quando presente, ocorre apenas quando os dentes são expostos as trocas térmicas, nos primeiros dias de tratamento e nas primeiras horas após a remoção da placa. A sensibilidade dental pode ter efeitos adversos frequentemente identificados durante o tratamento clareador, 
especialmente quando se utiliza peróxidos mais concentrados, sendo capaz de variar de sensibilidade leve a sensibilidade severa, sendo que sua intensidade diminui com o passar do tempo, não ultrapassando de 48 horas. Pesquisas clínicas mostram que $15 \%$ a $78 \%$ dos pacientes que tiveram seus dentes clareados relataram hipersensibilidade trans e pós-tratamento clareador (SILVA FMM, et al., 2012; CARDOSO PEC, et al., 2014; PONTAROLLO GD e COOPLA FM, 2019).

A sensibilidade dentinária ocorre devido à desobliteração dos poros do esmalte que favorece o aumento da comunicação do meio externo com o tecido dentinário, por esse motivo, o livre trânsito das substâncias de baixo peso molecular dos agentes clareadores, as variações térmicas, mecânicas em hidrogeniônicas (ingestão de alimentos ácidos ou gaseificados) são capazes de sensibilizar a polpa, via túbulos dentinários, , está se caracteriza por uma dor aguda, de curta duração, que varia desde um leve desconforto até a dor extrema. A outra teoria proposta é da hidrodinâmica, que assume que um estímulo aplicado na superfície da dentina causa o movimento do fluido tubular, que por sua vez ativa nervos mecanorreceptores, provocando dor e desconforto (Figura 1), e o dano ao tecido pulpar causado pelo clareamento dental provavelmente leva à liberação de fatores derivados de células, como trifosfato de adenosina e prostaglandinas, que excitam ou sensibilizam os nociceptores pulpares (ROCHA CS, et al., 2016; PAULA E, et al., 2013).

Outros autores relatam que esta sensibilidade pode estar relacionada a fatores endógenos, concentração e tempos do procedimento clareador, a técnica empregada, ou ainda, a todos esses fatores de forma sinérgica, sendo assim, a ingestão de certos tipos de alimento como por exemplo os alimentos gelados, ácidos, podem gerar uma dor aguda de curta duração, causando assim incomodo para o paciente e afetando na qualidade de vida do mesmo (GOMES CS, et al., 2015; CAVALCANTE SP, et al., 2019). Alguns métodos para prevenção são adotados para a sensibilidade dentária nas diferentes etapas do clareamento dentário caseiro (Quadro 2). Entre os métodos, o uso os dessensibilizantes são comumente utilizados, sendo eles os fluoretos, que diminuem a sensibilidade pela obstrução dos túbulos dentinários, e o nitrato de potássio, que diminui a habilidade das fibras nervosas da polpa dentária em transmitir a dor. (GARCIA EJ, et a., 2012).

$\mathrm{Na}$ tentativa de diminuir ou limitar a sensibilidade dentária durante o clareamento, vários agentes dessensibilizantes diferentes foram introduzidos para uso antes ou após o clareamento ou em associação com géis clareadores (KUTUK ZB, et al., 2019). Para controlar ou até mesmo reduzir a sensibilidade dentária nos pacientes, tratamentos com agentes dessensibilizantes, e uso de géis clareados (gluconato de cálcio), foram adicionados ao tratamento do clareamento dental, para evitar o incomodo ao paciente, mesmo sendo uma sensibilidade reversível que desaparece ao passar do tempo (CRESCENTE CL e PINTO CF, 2016).

Figura 1 - Esquema da desobliteração dos túbulos dentinários.

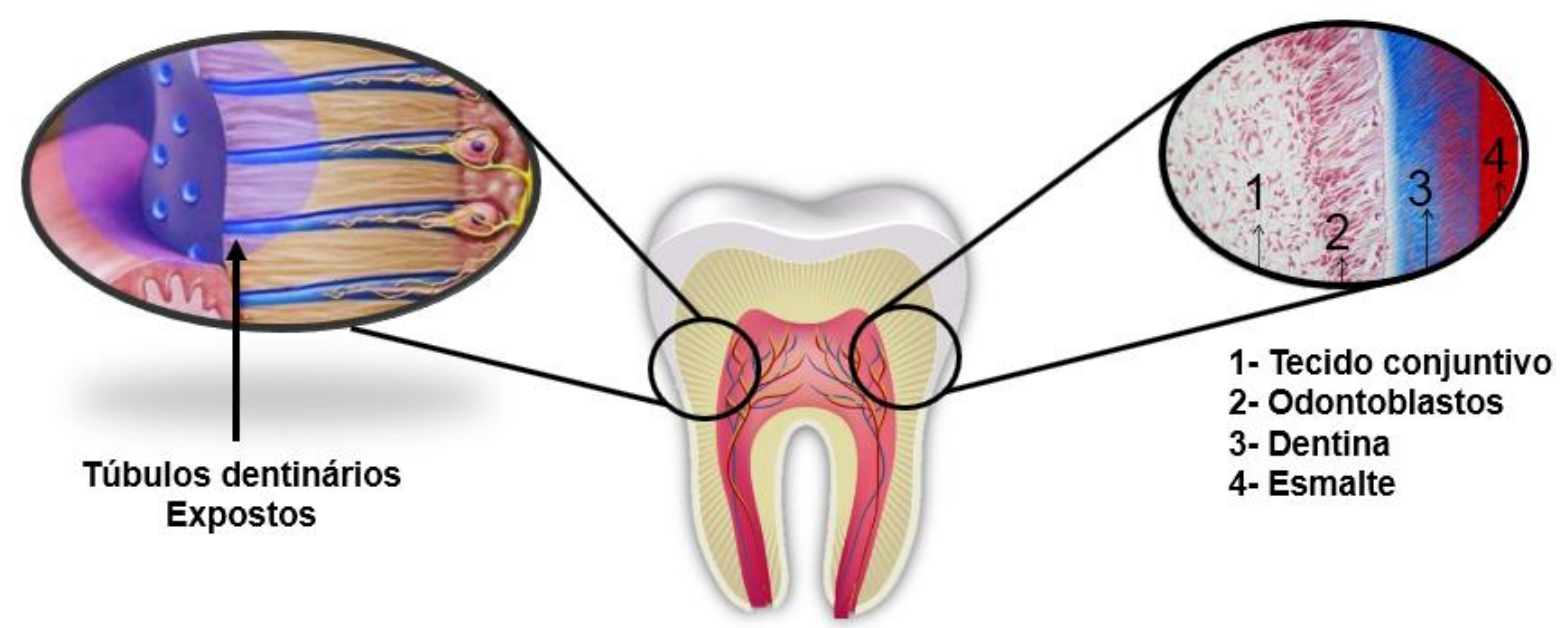

Nota: Imagem elaborada no PowerPoint.

Fonte: Palma FAM, et al., 2021. 
Quadro 2 - Métodos de prevenção são para a sensibilidade dentária nas diferentes etapas do clareamento dentário Caseiro.

\begin{tabular}{|c|c|c|}
\hline Pré-tratamento & Transoperatória & Pós-tratamento \\
\hline $\begin{array}{c}\text { Utilizar uma medicação sistêmica: } \\
\text { analgésicos anti-inflamatórios 30 } \\
\text { minutos antes }\end{array}$ & $\begin{array}{c}\text { Escolha da concentração } \\
\text { adequada para uso do produto }\end{array}$ & Medicação sistêmica \\
\hline $\begin{array}{c}\text { Utilizar uma medicação tópica: } \\
\text { apenas flúor ou } \\
\text { dessensibilizantes }\end{array}$ & $\begin{array}{c}\text { Tempo de uso e tipo da moldeira } \\
\text { de clareamento caseiro }\end{array}$ & Medicaão tópica \\
\hline $\begin{array}{c}\text { Escolha o agente clareador de } \\
\text { acordo com a concentração e } \\
\text { tempo adequado }\end{array}$ & $\begin{array}{c}\text { Uso de dessensibilizantes } \\
\text { associados aos produtos de } \\
\text { clareamento }\end{array}$ & \begin{tabular}{c} 
Medica \\
\hline
\end{tabular}
\end{tabular}

Fonte: Palma FAM, et al., 2021; adaptado de Garcia EJ, et al., 2012.

\section{Agentes dessensibilizantes}

Partindo da teoria da hidrodinâmica para a sensibilidade dentinária, onde fluido tubular, que por sua vez ativa nervos mecanorreceptores, provocando dor e desconforto, tratamentos para hipersensibilidade deve ocluir os túbulos dentinários e prevenir a sensibilidade do nervo. Portanto, alguns produtos têm foi indicada para tratar a hipersensibilidade dentinária devido à sua capacidade de ocluir túbulos. A principal função dos agentes dessensibilizantes e obliterar os túbulos dentinários, e entre os dessensibilizantes principais de ação obliteradora podemos incluir: os oxalatos de potássio, onde os mesmos irão reagir com os íons de cálcio da dentina, e com a isso a dentina irá formar cristais de oxalato de cálcio dentro dos túbulos dentinários e sobre a superfície da dentina, ocorrendo a obliteração dos túbulos dentinários (CAVALCANTE SP, et al., 2019).

Outro dessensibilizante de ação obliteradora é o glutaraldeído, que atua na coagulação de proteínas presentes nos canalículos dentinários, resultando em um precipitado de albumina sérica realizando a obliteração dos mesmos. Se torna mais efetiva quando se associada ao hidroxietil-metacrilato (HEMA), que acabam sendo polimerizados pela a albuminas, aumentando a eficiência da obliteração dos canalículos dentinários (RIBEIRO PJT, et al., 2016).

O dessensibilizante pelo composto de arginina forma um tipo de plug mineral quando associada ao carbonato de cálcio, formando um mineral rico em cálcio, fazendo com que ocorra a obliteração dos túbulos dentinários. Disponíveis comercialmente na forma de dentifrícios (CAVALCANTE SP, et al., 2019; RIBEIRO PJT, et al., 2016).

Os compostos a base de cálcio, que precipitam íons cálcio sobre a estrutura de dentina, que diante do processo de desmineralização perdeu cálcio e fosfato, promovendo à formação de hidroxiapatita e obliteração tubular, Apesar de sua eficácia ser imediata, a ação do Hidróxido de Cálcio diminui rapidamente, exigindo múltiplas aplicações para manter a sua efetividade (CAVALCANTE SP, et al., 2019; GOMES LMG, et al., 2020).

Vernizes e selantes, assim como resinas, adesivos e cimento de ionômero de vidrocriam uma barreira mecânica impermeabilizante aderida a dentina que sela os túbulos dentinários expostos. Possui a vantagem de atuar como fonte de compostos fluoretados. A camada híbrida, formada pela impregnação de monômeros na superfície dentinária desmineralizada, promove o selamento dos túbulos, limitando a movimentação do fluido intratubular (CAVALCANTE SP, et al., 2019; RIBEIRO PJT, et al., 2016).

Existem os lasers de alta potência, conhecidos como o High-Intensity Laser Treatment (HILT) encontramos o Neodímio Ytrio Alumínio Granada (Nd:YAG) e o de Dióxido de Carbono (C02), todos esses citados são de alta potência, que atua através da realização de uma fundição e recristalização da dentina que está exposta ao meio através da irradiação direta, ou seja, trabalham na dentina através de efeitos fototérmicos, aquecendo e derretendo a superfície do tecido duro. Quando a dentina esfria, recristaliza, obliterando os túbulos dentinários (ROCHA AO, et al., 2020). 
Já como exemplos de lasers de baixa potência ou Low-Intensity Laser Treatment (LILT) tem-se os de meio gasoso, como o de Hélio-Neônio (He-Ne) e os de diodo, como o Arsenieto de Gálio e Alumínio (AsGaAl), que atuam através de diferentes mecanismos, dependentes da potência e da interação do comprimento de onda com o tecido alvo, não é baseada em aquecimento (GOMES LMG, et al., 2020).

Existe um amplo comércio de produtos no mercado, diante dessa ampla variedade de produtos, Gomes LMG, et al. (2020) realizou um levantamento de substâncias dessensibilizantes encontradas atualmente no comércio, com as respectivas substâncias ativas, mecanismo envolvido/ação e sua posologia, a título de alguns exemplos, pois existem muito mais, podem ser visualizadas no Quadro 3.

Quadro 3 - Produtos dessensibilizantes comercializados, substâncias ativas, a posologia e mecanismos de ação.

\begin{tabular}{|c|c|c|c|c|}
\hline Tipo & $\begin{array}{c}\text { Nome comercial } \\
\text { (fabricante) }\end{array}$ & Substâncias ativas & Posologia & Ação \\
\hline \multirow{4}{*}{ Dentifrícios } & $\begin{array}{l}\text { Colgate sensitive pro- } \\
\text { alivio imediato }\end{array}$ & Arginina & \multirow{4}{*}{$\begin{array}{l}\text { Escovação diária; } \\
\text { Aplicar e } \\
\text { massagear no } \\
\text { dente sensível por } \\
1 \text { minuto. }\end{array}$} & \multirow{4}{*}{$\begin{array}{c}\text { Obliteradora e } \\
\text { neural }\end{array}$} \\
\hline & Sensodyne Original & Cloreto de estrôncio & & \\
\hline & $\begin{array}{c}\text { Elmex sensitive } \\
\text { Professional }\end{array}$ & $\begin{array}{c}\text { Arginina; } \\
\text { Carbonato de cálcio }\end{array}$ & & \\
\hline & $\begin{array}{l}\text { Sorriso dentes } \\
\text { brancos }\end{array}$ & Carbonato de cálcio & & \\
\hline \multirow{2}{*}{$\begin{array}{l}\text { Compósitos } \\
\text { Fluoretados } \\
\text { (Uso em } \\
\text { consultório) }\end{array}$} & SensiKin Gel Oral & $\begin{array}{l}\text { Fluoreto de sódio; } \\
\text { Nitrato de potássio }\end{array}$ & \multirow{2}{*}{$\begin{array}{l}\text { Tratamentos em } \\
\text { consultório e há a } \\
\text { necessidade de } \\
\text { ser supervisionado } \\
\text { pelo cirurgião- } \\
\text { dentista. }\end{array}$} & \multirow{4}{*}{$\begin{array}{c}\text { Obliteradora e } \\
\text { neural }\end{array}$} \\
\hline & $\begin{array}{l}\text { Verniz de flúor } \\
\text { Duraphat Colgate }\end{array}$ & Fluoreto de sódio & & \\
\hline \multirow{2}{*}{$\begin{array}{c}\text { Compósitos } \\
\text { Fluoretados } \\
\text { (Uso caseiro } \\
- \\
\text { enxaguantes) }\end{array}$} & $\begin{array}{l}\text { Enxaguante bucal } \\
\text { Orthogard Colgate }\end{array}$ & $\begin{array}{l}\text { Fluoreto de sódio; } \\
\text { Flúor fostato } \\
\text { acidulado }\end{array}$ & \multirow{2}{*}{$\begin{array}{c}\text { Bochecho } 1 x \text { ao } \\
\text { dia após a } \\
\text { escovação dos } \\
\text { dentes. }\end{array}$} & \\
\hline & $\begin{array}{c}\text { Colgate Plax; } \\
\text { Oral B complete; } \\
\text { Elmex Sensitive; } \\
\text { Sensodyne Cool Mint }\end{array}$ & Fluoreto de sódio & & \\
\hline $\begin{array}{c}\text { Oxalatos } \\
\text { (Uso em } \\
\text { consultório) }\end{array}$ & $\begin{array}{c}\text { Desensibilize KF } 2 \% \\
\text { (FGM) }\end{array}$ & Oxalato de potássio & $\begin{array}{c}\text { Não deve } \\
\text { exceeder } 1 x \text { ao dia } \\
\text { e recomenda-se }\end{array}$ & \multirow{2}{*}{ Obliteradora } \\
\hline $\begin{array}{c}\text { Oxalato } \\
\text { (Uso caseiro) }\end{array}$ & $\begin{array}{c}\text { Desensibilize } \\
\mathrm{KF} 0,2 \% \text { (FGM) } \\
\end{array}$ & & $\begin{array}{l}\text { acompanhado pelo } \\
\text { cirurgião-dentista. }\end{array}$ & \\
\hline \multirow[b]{2}{*}{$\begin{array}{l}\text { Agentes com } \\
\text { glutaraldeído }\end{array}$} & $\begin{array}{c}\text { Gluma Desensitizer }{ }^{\circledR} \\
\text { (Heraeuz Kulzer) }\end{array}$ & Glutaraldeído & \multirow[b]{2}{*}{$\begin{array}{c}\text { Aplicação passo } \\
\text { único e } \\
\text { consultório. }\end{array}$} & \multirow[b]{2}{*}{ Obliteradora } \\
\hline & $\begin{array}{c}\text { Telio CS } \\
\text { Desensitizer® } \\
\text { (Ivoclar Vivadent) }\end{array}$ & $\begin{array}{l}\text { Glicoldimetacrilato de } \\
\text { polietileno; } \\
\text { Glutaraldeído em } \\
\text { solução aquosa } \\
\end{array}$ & & \\
\hline Biovidro & Biosilicate (Biossilex) & $\begin{array}{c}\text { Biossilicato } \\
\text { Calcinada } \\
\end{array}$ & $\begin{array}{l}\text { Deve ser aplicado } \\
\text { em consultório }\end{array}$ & Obliteradora \\
\hline Adesivo & $\begin{array}{c}\text { Adper single bond } \\
\text { 3M; } \\
\text { Adesivo clearfil se } \\
\text { bond Kuraray } \\
\end{array}$ & Bis-GMA & $\begin{array}{l}\text { Aplicar mais de } \\
\text { uma camada. } \\
\text { Deve ser feito em } \\
\text { consultório. }\end{array}$ & Obliteradora \\
\hline
\end{tabular}

Fonte: Palma FAM, et al., 2021; adaptado de Gomes LMG, et al., 2020.

\section{Utilização de dessensibilizantes pré clareamento dentário e pós clareamento dentário}

Uma das alternativas para controlar ou diminuir a sensibilidade dentária após ou durante um tratamento clareador é a utilização de dessensibilizantes, e o uso de dentifŕcios dessensibilizantes contendo $5 \%$ de nitrato de potássio, podem diminuir ou controlar a sensibilidade, desta forma, durante o preparo do paciente 
para o clareamento, deve-se solicitar que o mesmo escove seus dentes com dentifrício dessensibilizante, sendo uma simples solução clinicamente comprovada. Segundo Ferreira DO, et al. (2014); demonstrou em seu estudo que o uso dos dentifrícios não afetou a eficácia do clareamento e para a sensibilidade dental houve diferença, demonstrando que o nitrato de potássio $5 \%$ foi mais efetivo na redução da sensibilidade dental percebida pelos pacientes em uma semana.

Partindo para a utilização de géis dessensibilizantes, Tay LY, et al. (2014); realizou um estudo para avaliar se $o$ uso de um agente dessensibilizante antes do clareamento em consultório diminuiria a sensibilidade, e o mesmo constatou que o uso de um gel dessensibilizante ( $5 \%$ de nitrato de potássio/ $2 \%$ de fluoreto de sódio) antes do clareamento em consultório não afetou a eficácia de branqueamento, mas foi capaz de reduzir a sensibilidade dos dentes nos tratamento de clareamento emconsultório, ou seja, géis dessensibilizantes com concentrações de $5 \%$ de nitrato de potássio/ $2 \%$ de fluoreto de sódio pode reduzir a incidência e intensidade de sensibilidade dentária sem reduzir a eficácia branqueamento em consultório.

O estudo de meta-análise de Wang T, et al. (2015); foi realizada para avaliar a eficácia de agentes dessensibilizantes, e reforça o estudo de Tay LY, et al. (2014); onde o nitrato de potássio e fluoreto de sódio foram indicados previamente para tratamentos de clareamento dental para aliviar a sensibilidade dentária, e géis dessensibilizantes de nitrato de potássio e o fluoreto de sódio reduzem a sensibilidade dentária, enquanto nenhuma conclusão consistente sobre a mudança da cor do dente foi encontrada. $O$ uso de um gel dessensibilizante ( $5 \%$ de nitrato de potássio, $2 \%$ de fluoreto de sódio) antes do clareamento dental em pacientes com restaurações de resina composta não reduz a prevalência de sensibilidade dentária, mas reduz a intensidade da sensibilidade dentária durante o clareamento (BONAFÉ E, et al., 2014).

Em um estudo parecido aos anteriores foi realizado por Reis A, et al. (2011), onde o mesmo através de um estudo clínico avaliou o efeito da aplicação de um agente dessensibilizante ( $5 \%$ de nitrato de potássio/ $2 \%$ de fluoreto de sódio) previamente ao clareamento de consultório, e se diferencia dos estudos anteriores, é que ocorreu uma ativação LED/laser. Diante dos resultados o autor concluiu que 0 uso de gel dessensibilizante antes do clareamento de consultório não previne a sensibilidade dental, mas pode reduzir a duração desse efeito colateral. Já no estudo Gomes CS, et al. (2015); o autor observa ainda que o uso de dessensibilizantes vem apresentando melhores resultados quando comparado ao uso de analgésicos e antiinflamatórios. O mesmo utilizou dessensibilizante diário com gel à base de nitrato de potássio e flúor previamente ao tratamento clareador.

O estudo Cerqueira RR, et al. (2013); demonstrou que onde não houve redução da prevalência da sensibilidade dental com o uso de dessensibilizante à base de nitrato de potássio $5 \%$ e fluoreto de sódio $2 \%$ antes do clareamento, os quais não evidenciaram redução na prevalência da sensibilidade dentária. $\mathrm{O}$ uso de agente dessensibilizante previamente ao clareamento de consultório com $\mathrm{PH} 20 \%$ não interferiu na efetividade do clareamento dental e não reduziu a prevalência e a intensidade da sensibilidade dental.

Os agentes dessensibilizantes mostram redução efetiva na incidência e intensidade da sensibilidade após um clareamento de dentes vitais em consultório (NANJUNDASETTY JK e ASHRAFULLA M, 2016). O uso de agentes dessensibilizantes como flúor e nitrato de potássio antes ou após o clareamento foi capaz de reduzir a experiência de sensibilidade dentária durante o tratamento clareador (PAULA E, et al., 2013). Entretanto a técnica com comprovação de eficácia indicada por estudos clínicos controlados indica 0 uso de géis dessensibilizantes previamente ao clareamento em consultório (FERREIRA DO, et al., 2014; NANJUNDASETTY JK e ASHRAFULLA M, 2016).

\section{CONSIDERAÇÕES FINAIS}

Diante da revisão realizada, podemos considerar que a sensibilidade dentinária ocorre devido à desobliteração dos poros do esmalte que favorece o aumento da comunicação do meio externo com o tecido dentinário. Existem tratamentos para reduzir a sensibilidade, como por exemplo o uso de laser de baixa e alta potência, mas os mais utilizados são os agentes dessensibilizantes é eficaz para tratamento da sensibilidade dentária após o tratamento de clareamento, sendo caseiro ou de consultório, e que $5 \%$ de nitrato de potássio / $2 \%$ de fluoreto de sódio pode reduzir a incidência e intensidade de sensibilidade dentária sem reduzir a eficácia branqueamento em consultório. 


\section{REFERENCIAS}

1. BARBOSA DC, et al. Estudo comparativo entre as técnicas de clareamento dental em consultório e clareamento dental caseiro supervisionado em dentes vitais: uma revisão de literatura. Revista de Odontologia da Universidade Cidade de São Paulo, 2017; 27(3): 244-252.

2. BONAFÉ E, et al. Effectiveness of a desensitizing agent before in-office tooth bleaching in restored teeth. Clinical oral investigations, 2014; 18(3): 839-845.

3. CARDOSO PEC, et al. Perguntas e respostas sobre o clareamento dental. Revista da Associação Paulista de Cirurgiões Dentistas, 2014; 68(3): 236-237.

4. CAVALCANTE SP, et al. Efetividade de diferentes tipos de tratamento no controle da hipersensibilidade dentinária cervical. Revista Uningá, 2019; 56(7): 68-79.

5. CERQUEIRA RR, et al. Efeito do uso de agente dessensibilizante na efetividade do clareamento e na sensibilidade dental. Revista da Associação Paulista de Cirurgiões Dentistas, 2013; 67(1): 64-67.

6. CRESCENTE CL, PINTO CF. Análise da sensibilidade após o uso prévio de dessensibilizantes em clareamento dental. Revista Brasileira de Odontologia, 2016; 73(1): 34.

7. FERREIRA DO, et al. Estudo da dessensibilização prévia ao clareamento dental em consultório: uma revisão de literatura. Revista da Faculdade de Odontologia da UFBA, 2014; 44(1).

8. GARCIA EJ, et al. Associação de técnicas para diminuição da sensibilidade advinda do clareamento caseiro. Revista Dental Press de Estética, 2012; 9(4).

9. GOMES CS, et al. Avaliação de hipersensibilidade dentinária em função do procedimento clareador: revisão de literatura. Revista Brasileira de Odontologia, 2015; 71(2): 194.

10. GOMES LMG. Mecanismos de ação dos agentes terapêuticos empregados no tratamento da hipersensibilidade dentinária, 2020.

11. KUTUK ZB, et al. Effects of in-office bleaching agent combined with different desensitizing agents on enamel. Journal of Applied Oral Science, 2019; 27.

12. NANJUNDASETTY JK, ASHRAFULLA M. Efficacy of desensitizing agents on postoperative sensitivity following an inoffice vital tooth bleaching: A randomized controlled clinical trial. Journal of conservative dentistry: JCD, 2016; 19(3): 207.

13. OLIVEIRA JAG, et al. Clareamento dentário $x$ autoestima $x$ autoimagem. Archives of Health Investigation, 2014; 3(2).

14. PAULA E, et al. The effect of perioperative ibuprofen use on tooth sensitivity caused by in-office bleaching. Operative dentistry, 2013; 38(6): 601-608.

15. PONTAROLLO GD, COPPLA FM. Estratégias para redução da sensibilidade dental após clareamento: revisão de literatura. Revista Journal of Health, 2019; 1.

16. REIS A, et al. Assessment of tooth sensitivity using a desensitizer before light-activated bleaching. Operative dentistry, $2021 ; 36(1): 12-17$.

17. REZENDE M, et al. Clareamento dental-efeito da técnica sobre a sensibilidade dental e efetividade. Revista da Associação Paulista de Cirurgiões Dentistas, 2014; 68(3): 208-212.

18. RIBEIRO PJT, et al. Mecanismos de ação dos recursos terapêuticos disponíveis para o tratamento da hipersensibilidade dentinária cervical. Odontologia Clínico-Científica (Online), 2016; 15(2): 83-90.

19. ROCHA AO, et al. A utilização da laserterapia para o controle da hipersensibilidade dentinária: uma revisão sistematizada da literatura. Revista Eletrônica Acervo Odontológico, 2020; 2: e3907,

20. ROCHA CS, et al. Efeito de agentes dessensibilizantes na obliteração dos túbulos dentinários-estudo in vitro. Revista Brasileira de Odontologia, 2016; 73(4): 272.

21. SILVA FMM, et al. Avaliação clínica de dois sistemas de clareamento dental. Revista Odontológica do Brasil Central, 2012; $21(57)$.

22. TAY LY, et al. Assessing the effect of a desensitizing agent used before in-office tooth bleaching. The Journal of the American Dental Association, 2014; 140(10): 01245-1251.

23. WANG Y, et al. Evaluation of the efficacy of potassium nitrate and sodium fluoride as desensitizing agents during tooth bleaching treatment-A systematic review and meta-analysis. Journal of dentistry, 2015; 43(8): 913-923. 